\title{
Lewensbeskoulike differensiasie in die onderwys*
}

\author{
B.C. SCHUTTE \\ Departement Fundamentele Opioedhunde, Pl/vir CHO
}

\begin{abstract}
The fact that for many people the $\mathcal{N}$ in CNE (Christian National Education) often became more important than the $\mathrm{C}$ may be ascribed to a historical process. Opponents of the whole concept also did not understand that the C'hristian Afrikaner wanted a Christian education for his own childreu, and did not begrudye other people "other" education. The concept "National", houever, has become a bogyman, and has come to be interpreted in terms of the "National Party".
\end{abstract}

The concept of foundational/ religious differentiation is mooted as the first criterion, because il covers the tolal spectrum of human education (Christian, cultural, ethnic, elc.). Supplemented by ethnic differentiation it should suffice to cover the whole field of education in the RSA. The importance of the possibility of parental authority is discussed as well. The achievement of parity he various national groups is also seen to be possible along these lines.

Sedert die laaste kwart van die vorige een of nog vioeër het ons hier verskillende organisasies en bewegings gelıad wat die saak van die Christelike en die nasionale in die onderwys sterk bevorder het - ons kan hulle CNO-bewegings noem. Hierdie bewegings is soms kerklik geïnspircer; wat die klem sowel op die Christelike as op die nasionale laat val het. Die kerke in Suid-Afrika het egter 'n leeuedecl van die nasionale stryd - die stryd om nasiewording en nasiewees - vir hulle rekening geneem. Hierdie kerklike bemoeiing was soms van so' 'n aard dat dit moeilik was on te glo dat die hoofsaak nie die nasionale was nie, met die (Christelike slegs as 'n verdere motivering daarby.

- Openingsrede by COVSA-kongres op I7 Januarie I9\&I.

Koers, $46(3) 1981$ 


\section{n.C. Schutte}

Dat tlit so is, is natuurlik nic onverwags nic. Die kerk het uit Christene brstaan wic se (hristcnskap nie besonders bedreig was nic: daar was geen georganiseercle aksie meer tecen die kerk nie. Die $A$ frikaners het in dic kerk 'n veilige hawe gehad warmec hulle 'n intieme verband behou hel. Dic beocfening van die Cliristclike in dic onderwys was 'n byna vanselfspickente praktyk. So gemaklik het dit egter nie met die nasionale gegaan nic. Roudom dic nasionale was daar amptelike miskenning van Afrikaans (vrocër Hollands) as taal, van dic nasionale strewc op politicke gebied, van die nasionale strewe op ckonomicse gebict en van die begecrte van dic Alrikancroucr dat sy kind in sý kulluur opgevocd moct word. Hierdic tcenstand Icen die uitlewing van sy opkomende nasionale gevoel het egter ook sy kerklike implikasies gehad. Wic vir volk en vaderland verlore is, vocl spocelig in dic $\Lambda$ frikaanse kerk ontuis. Dic kerk was dus terdeč gemotiveerd in sy stryd vir nasionale sellbehoud, vir nasionale onderwys dus.

Dit is eers in die cerstc kwart van die vorige ceu dat die skoolstryd werklik die nasionale tericin betree het toe die Britse verengelsingsbeleid deur Somerset hier in sy volle draagwydte deurgevoer is. Om die Bocre te verengels moes hulle geleer word om hulle patriot isme op Engeland oor te plaas. Dit kon egter nie gebeur solank die Calvinisticse lewensvisie by hulle oorheersend was nic. Die religieuse strydmiddel is daarom aangewend om die politieke liberalisticse lewensiening te laat posvat: verwyder die godsdiens uit die skool. U sien dat die religieuse (Christelike) hier aangeval is om die nasioale strewe le beheers en van tuis na "home" te verander. Dest yds (en tot baie ver in die huidige ecu) was dit, sover dit onderwys betref het, slegs Afrikaners en Engelse wat in dlie prentjie verskyn het, en by hulle was die teëstelling: nasionaal cn "home". Elkcen is (later) of as 'n Nat (nasionaal) of as 'n SAP (nie nasionaal nie, nic SA cerste cn enigste nic) beskou. Die "nasionaal" van Christelik-nasionaal was dus vir baie mense, sowel die voorstanders as die trenstanders, sinonicm met dic politicke "nasionaal" van die Nasionale Party. Dit, ten minste, is hoc dit vir die oppervlakkige waarneıner gelyk het wat nic die dicpere motiewe van die CNO-beweging geken het of dit nie in sy uitwerking verstaan het nic. Tog het baic voorstanders en teěstanders nie begryp dat wat die Afrikaner as nasionaal gesien het, met sy belydenis gest rnok het terwyl hy sy teëstander'n eie siening gegun het wat weer met sy lewensvisic gestrook het nie.

Daar was ook CNO-bewegings wat nic kerklik nic maar maatskaplik, kulturcel, professioncel en selfs politics geïnspireer was. As daar na die grondwette of aksieprogramme van die Afrikaanse onderwysverenigings (TO, SAUU, OVSOV, NOU) gekyk word, sal eksplisiet en implisiet verbon- 
denheid aan die CNO-beginsel opgennerk word. Dink aan die AfrikaansChristelike Debatsverenigings, aan die FAK, ja, selfs aan verskeie huidige en gewese politieke partye, dan kom bulle bondgenootskap in die CNOstryd ondubbelsinnig na vore. So het die baie belangrike Instituut vir CNO (ICNO) van die FAK in 1948 met sy rigtinggewende verklaring Cihristeliknasionale Onderwysbeleid'n geweldige rol gespeel on die Afrikaners eensgesind met betrekking tot die saak te stem.

Na die duidelike formulering van die CNO-beleid deur die ICANO van die FAK in 1948 en 'n verenigde front by die Afrikanervolk na die oorname van die regering deur die Nasionale Party en by die Afrikaanse Kerk (IKKO) was die grondslag vir welslae vorentoe gelê. Met die oorname van die regering deur dic Nasionale Party was die pad landswyd gehaan vir toepassing van die CNO-beginsels in onderwyswette eu-praktyk. Dit het in 1967 gebeur met Wet 39 vall 1967, wat onderwys vir Blankes reël. Hierdie wet het onderwys aan alle skole wat onder die staat ressorteer, Christelik verklaar (sonder 'n enkele uitsondering) en ook die nasionale beginsel verskans. Die staat (Minister van Nasionale Opvoeding) het spoedig 'in konnotasie aan die term Cihristelik as kenmerk van elke Blankeskool gegec wat konserwatiewe Afrikaners grootliks bevredig. Dit is dan nou die sland van sake by Blanke-onderwys en in vooruitsig vir die tydperk wat op die RGN-verslag volg.

\section{COVSA}

Met die stigting van die Christelike Opvoedkundevereniging van SuidAfrika (COVSA) in die vroeě sewentigerjare het daay in die aksie dusver' $n$ nuwe dimensie gekom. Al dui die naam slegs op Opvoedkunde as wetenskap, toon die grondwet duidelik dat COVSA eweseer begaan is our die praktyk van die opvoedkunde, naamlik die onderwys in prakıyk en die ouer as noodsaaklike vennoot in die opvoeding. En $10 \mathrm{~g}$ kom die woord nasionaal nêrens daarin voor nie. Dit is doelbewus gedoen maar beslis nie: omdat "die nasionale", die volkseie, die kultuurgelondenheid, die Afrikaanse vir die stigters onbelangrik of selfs minder belangrik was nic; inteendeel, dit is juis omdat hulle besef het dat die destydse bestaande "nasionale" in "CNO" soveel skadelike verwerping weens waninterpretasic meegebring het dat hulle besluit het om die term as oorbodig weg te laat. Dit het 'n paaiboelic en 'n skelnaam geword (soos "apartheid" vandag).

Hockom oorbodig? Vir dic Christen-Afrikaner is dit onomstootlik duidelik dat Christen-wees hoegenaand nie volkscie uitskakel nie maar dit slegs in 


\section{B.C. Schutte}

die regte perspekticf plaas. Daar is sovecl ander terreine waar die onderwys onk Chiristclik moct wecs: Christclik-maatskaplik, Christelik-wetenskaplik, Christelik-scdelik, Chıristclik-juridies, Christclik-ckonomics - ja, in elk en icter aspek van dic onderwys moet dit Ghristelik wecs, dus ook in dic nasionale. Weglating van die nasionale uit COVSA se grondwet gee dus werklik niks prys nic naar bring besliste wins. Wie Christen is, sế in een ascm dat hy in 'n verband inet medegelowiges staan; dat hy daar staan as kind van sy oucrs (wat hy erken, respektecr cn licllet); dat hy saam met sy ouers 'n sckerc moedertaal prant (wat dinge so sê dat hy dit kan waardeer, respektecr en annvar); dat sowel sy ouers as sy taal diep in 'n kultuur gewortel is (waarin hy opgegroci het en tuis voel); dat hierdie kultuur baie met ancler kulture genıcen het maar ook feitlik op elke gebied van hulle verskil, veral in dic belewing en interpretasie daarvan. Wie Clıristen sê, sê daarmee saam dus ook nasionale mens, kulturele mens, Afrikaner (Engels, Joods, Klcurling, Indiër, Xlıosa, Zoeloc cnsovoor(s) - volkseie mens dus. Wie hicrdic onwegelenkbare gebondenheid aan die eie (of as eie aanvaarde) prysgee, $m$ is dic uitkyk punt vanwaar die perspektief moontlik word. Vandaar uit kyk hy in die lig van God se Woord, met oẻ wat deur Woord en Gees verlig is op 'n tcrrein wat deur God se Woord en Gces belig is. As hy nie dáár staan nie, kyk hy noodwendig skeef en sal sy gesigsbeelde verdraai en selfs verwar word. So dien elke Christen, of hy Wit of Swart is, of hy hier woon of elders op die aardbol, dic dinge wat van belang is. In hierdie lig gesien, is die term nasionaal oorbodig en ' 11 remskoen vir samewerking. Ons kom hierop weer tcrug.

Hierdie benadering het COVSA konsekwent voorgestaan en bevorder en glo daarmee dat hy nog op die "ou paaie" is, nog op die CNO-pad is. Wat staan CNO dan werklik voor?

\section{DIE KERN VAN GNO}

In sy diepste wese wil voorstanders van CNO net vir hulle eie kinders iets bepleit, iets wat hulle reg is en aan niemand anders enige albrcuk doen nie. Wie met hom nic saamstem nie, weet immers wat vir homself dic beste is, en staan dit dan voor sonder dat dit hom verkwalik word. CNO eis dus vir Christenkinders Cluristelike onderwys, omdat dit Goddelike eis is en omdat dit vir hulle die enigste ware onderwys is. Om vir hicrdie kind waar te wees moet dit met sy hartstocrusting sinchroniscer en moet dit opvocdkundig eg wecs. Die hartstocrust ing word deur die lewens- en wêreldbcskouing gekleur en is dus religieus bepaal. Dit begin reeds met die aanvang van die lewe van dic kind vorm $\mathrm{cn}$ inhoud aanneem en is daarom met die totale verlede van 
die kind ineengeweef. Dit is dus onlosmaaklik produk van die huislike (ouerlike) geloof, sedes, kultuur en volkseie. Dit vereis dus volkome instemming van die formele en informele onderwys op hierdie noot.

Dit bring ons by die verdere hoeksteen van die beweging vir Christelike onderwys, naamlik dic onomstootlike ouerplig en ouerreg by die formele en nie-formele skoolonderrig. Die ouer stuur sy kind na die skool toe om daar deur diegene wat hy aangewys of goedgekeur het, te laat onderrig. Hierdie onderwyser word nie plaasvervanger van die ouer nie en kan dus nie ander sienswyses en beginsels op die kind afdruk as wat die ouer hom voorskryf en toelaat nie. Hy vul die ouer aan waar die se arm self te kort en sy kenuis, vaardigheid en beskikbare tyd onvoldoende is. Die ouer is en bly die verant woordelike persoon vir die onmondige kind wat aan hom toevertrou is.

Hieruit vloei voort dat die skool eintlik die ouer se skool is on sy kind opvoedend te onderrig in die gees en rigting soos deur hom bepaal, neergelé of gekontroleer. En omdat hy dit nie individueel prakties kan doen nie, noct die ouer in georganiseerde verband optree. Vanselfsprekend sal gelykgesinde ouers saamspan en sodoende vrye groepskole stig, beheer en onderhou - dit alles sonder om die aandeel van die staat wat eise vir sy opgroeiende burgertjies mag stel en wat geldelike veipligtinge in dic opsig het, te ontken.

Dic weglating van die term nasionaal uit die aksie van COVSA het dus absoluut niks prysgegee nie, omdat alles nog onder die vaandel "Cliristelike onderwys/skool" ten volle gedek is.

Kom ons kyk nou na die wins wat dit meegebring het.

\section{DIE UITDAGING VAN 1980}

Daar het teen die einde van die sewent igerjare op onderwysgebied in RSA soveel dinge gebeur dat ernstige herbesinning nodig geword het. Die gebeurtenisse was trouens ook so sterk polities gekleur dat die staat nie net lede oè mag gesit en toesien het nic. Ons dink aan die salarisstryd by Blanke-onderwys, die onderwystekort by alle onderwys, dic skoolboikotte by Kleurlinge en Swartes, met die begeleidende oprocer en geweldplegings en die voortdurende gehamer op paritcitsverskille by die verskillende verantwoordelike departemente. Dit het meegebring dal die stalus quo nie ineer sonder ingrypende aanpassings gehandliaafkan word nic. Dit het (ot dic op)- 


\section{B.G. Schutte}

dıag aan die R(GN annleiding gegec om indringende wetenskaplike ondersock na alle laselte van die nuderwys in die RSA in te stel en anubcvelings a an die Kabinet voor te. lê. Die RGN se opdrag was “... om 'n wetcnskaplike onclersock op gekoördincerde grondslag ua die onderwys in (lie RS $\Lambda$ in te stel, ... (daar) word gevra vir beginselriglyne wat 'n praktics uitvoerbare onderwysbeleid in die RSA moontlik sal mak ten einde

- sy inwoners se potensiaal te verwesenlik;

- die ckonomiese groci van die RSA te bevorder;

- dic lewensgehalte van al sy inwoners te verbeter, en

" 'n gelyke gehalte onderwys vir alle bcvolkingsgroepe te bereik"

(Uit stukke van dic RGN-konmissie).

Rrg geinterpretecr sou hicrdic opdrag neerkom op dic ontwerp van een enkele onderwysstelsel vir die RS $\Lambda$ waronder alle bevolkingsgroepe so ingeskakel word dat hulle onderskeic potensiale verwesenlik en hulle lewensvlak in belang van dic gehecl verbeter kan word. Dit was dan die byna boıncnslike taak wat aan die RGN-kommissie opgedra is.

Vir COVS $\Lambda$ was dit van die begin af duidelik dat in die opdrag die beginsel van cenheid en veclhcid, van diversiteit en geỉntegreerdheid, van enkelvormigheid en pluriformiteit op 'n verantwoorde wyse ingevleg moct word. Daar moes dus volgens 'n Calvinisticse fundering verskille erken en oorecnkomste gesock word. COVSA het van die standpunt uitgegaan dat alle onderwys normat ie op grondbeginsels berus en nooil neutraal kan wees nie. Dis nie moontlik om ware onderwys vir my kind te verkry as dit nic op my lewensbeskoulike grond gefundecr en gebou is nie. Dis ook, opvoedkundig gesien, vals om te beweer dat neutraliteit as eis vir gelykwaardigheid in onderwys gestel kan word. Neutraliteit kan by 'n ding aangetref word maar nooit by 'n mens nie. Sodra 'i mens (ouer, onderwyser, dosent) neutraal probeer wecs, verločn hy sy essensiële menswecs, sy unicke kenmerk van betrokkenheid, gebondenheid aan 'n oorsprong. Wat hy dan egter gerieflik vergeet, is dat hy slegs daardie oorsprong wat hy dusver bely het (die God van die Skrifte, die mens, die natuur, dic daad ensovoorts), verruil vir'n ander cen waarin hy nou glo, naamlik dic god neutralitcit.

Dis die hele mens wat onderwys gec - nic net sy verstand, kennis, wetenskap of professionele toerusting nie. Dit is ook die hele mens (hoewel nog onmondig) wat onderwys ont vang - nic net die brein of die psige of die sosiale of dic beroep nie. Die hele mens sluit dan as eerste en mees grondliggende beginsel sy religie in. Hicrdic religie bepaal vir hom alles in sy lewe cn sy werke: dit bepaal wie hy aanbid, hoe hy aanbid, hoe hy liefhet, 
hoe hy dink en doen, wat hy aanpak en wat hy laat, al sy keuses, sy voorkeure - ja, alles wat ooit met hom gebeur. "Two in a prison looked through the bars, the one saw mud, the other stars".

Hierdie waarheid dat die religie, die lewens- en wêreldbeskouing, die "hart", die ganse lewe en optrede totaal beheers, word vandag deur almal geglo, deur Skrifgelowiges en deur diegene wat in 'n ander god glo. (ieen neutralis wil sy kind graag iets anders sicn as 'n beter neutralis as liyself nie; geen humanis wil sy kind 'n materialis sien nie; geen wêreldbuiger wil sy kind ' $n$ eng nasionalis sien nie; geen nasionalis wil sy kind as verraaier sien nie. Verder, geen ouer wat nie slegter as 'n dier is nie, wil sy verantwoordelikheid vir sy kind ontken nie. Iewensheskoulike (ook genoem religieuse) fundering vir alle onderwys moet dus die eerste beginselriglyn wees. $O_{p}$ hierdie onderste laag van die fondament word dan die differensiasic toegepas wat nodig is om alle groepe te bevredig - lewensbeskoulike/ religieuse diflerensiasie dus.

Ons was oortuig dat ons nie weer die fout van 1967 moes herhaal toe ons by die skole vir Blankes "alle onderwys in skole wat onder die staat ressorteer", tot Christelike onderwys verklaar het nie. Daarmee het ons onder 'n grondwet wat geloofsuryheid waarborg, gewetensdwang aan die orde gestel. Die enigste uitweg sou wees om die begrip "Christelik" so wyd te omskryl dat dit eintlik vir niemand iets sê nie. IJit het egter nie geskied nie, want dic term is nogal omskryf in terme wat reformatoriese Christene bevredig. Die enigste ander wyse waarop Jode, ateiste en ander nie-Clıristene (Blankes natuurlik) hiermee genoee kan neem, is die feit dat die welbock en dic praktyk nie dieselfde taal praat nie, dat van ware Christelike opvoedende onderwys in skole so min teregkom dat andersdenkende ouers lulle kinders sonder gewetenswroeging daarheen kan stuur.

Onderwys by Blankes sou dus gereil kan word deur vir almal die eis van religieus (lewensbeskoulik) gefundeerde onderwys te stel. Daat sal dus skole vir die verskillende religieë moet wees (I.W nie vir die verskillende kerke nic; nie godsdiensgeoriënteerde skole nic, maar religicus gefundecrde skole). Ja, dis waar, wic nie saamstem nie, kan nog altyd sy kind in 'n privaatskool van sy keuse plaas maar mots dan op gecn staatsteım reken nie. Maar daarmee het ons ook die ouer prakties sy keusereg ontneem: die staat het vir hom gekies. Oor die aard en gehalte van die Christelike onderwys aan 'n skuol moes die staat toesig hou. Die staat het selfs teen die ouer se religieuse gewete in vir hom gekies (byvoorbeeld Chrislelike onderwys vir Jode). Iets soortgelyks vir die onderwys van alle bevolkingsgroepe sou nooit met welslae 


\section{B.G. Schutte}

drurgevoer kan word nie en noodwentig die stryd in heftigheid laat toenecm. Dit sal maklik dic wêrelılfiront tecn ons laat draai (as daar nog draaiing moontlik is!!). Dit sou atcīste, ongelowiges en alle ander religieuse grocpe tecn ons (die Blanke, die wetgewer) in die harnas jaag. (Daar sal 'n politieke strydpunt daarvan gemaak word, en ons sal ons nie kan verdedig nic.)

Tren hicrdie beginsel van lewensbeskoulike diflerensiasic het daar van die binnckring van die beweging vir Christelike onderwys in ons land ook sterk reaksic gekom. Daar word bewecr dat Christene tog die meerderheid van clic bevolking van die land uitmaak en ons daarom ons land as 'n Christelike land kan bestempel. In 'n Christelike land moet alle wette dan dic Clıristelike as norm annvar en al die ander as uitsonderinge behandel. Dic verlede het ons egter geleer dat die antipatic van sowel die Engelse medelourgers as van die ander bevolkingsgrocpe teen die Afrikaanse Blanke Calvinistiese benadering so groot is dat samewerking vonraf ondenkbaar is - dis vir hulle weer die Boere, die Blankes, dic Afrikaner wat die septer swaai en daarom beveg moet word - so het dit mos nog altyd met CNO gegaan.

'n Verdere beswaar het gekom van diegene wat bevrees was dat die keuse vir Christelike onderwys by lewensbeskoulike differensiasie nou aan die ouers oorgclaat word en hulle nic tot positiewe keuse in staat is of van dic implikasics bewus is nie. As dit werklik die geval is, dan beteken dit dat Christenouers dalk nic Christelike onderwys vir hulle kinders wil hê nie of hulle nog nooit daaroor rekenskap gegee het nie. Dan is ons stryd mos 'n verlore stryd en moct ons van voor af begin on eers die ouers te bearbci Intelat hulle dit wil hê. Hoc gouer dit gedoen word, hoe beter. Die toepassing van lewensbcskoulike differensiasie sal dan juis hierdie noodsaaklike taak verhaas en aktucel maak. Daar word met hierdie optrede 'n geweldige eis aan sowel ons ouers self as aan die kerk, die onderwyserskorps en die maatskappy gestel om ouers tot verantwoorde keuse te lei.

Daar is ook beswaar grmaak op grond van die feit dat ons vandag nie met die nodige besiclde onderwysers toegerus is om in die behocftes van spesifick Christelike skole soos deur oucrs verkies te voorsien nic. Is alle onderwysers by skole vir Blankes wat beslis as Christelik deur Wet 39 van 1967 gestempel is, dan nie daarvoor loegerus nic? En, indien nic, dan versterk dit ons argument dat ons moet oorgaan tot 'n stelsel waarin die ouers hulle regte en pligte kan/moct uitoefen en vir die geskikte leerkragte moet sorg. Vir dic Blankes (meer in besonder vir Afrikaanssprekendes) is daar tans genocg 
opleidingsinrigtings vir onderwysers wat positict ten opsigte van locrusting van onderwysers vir ware Christelike onderwys staan. Verreweg die meeste van hulle is aktief ingeskakel by die Koördinerende Komitee vir (ihristelike Onderwysaksie (KKCOA). Self's vir ons Engelse medeburgers is daar geen onoorbrugbare besware nie. Sover dit die ander bevolkingsgrocpe aangaan, lề daar 'n langer pad van stryd en bearbeiding voor.

\section{DIE ETNIESE/KULTURELE DIFFERENSIASIEBEGINSEL}

Daar is ook die volgende hindernis wat oorwin moet word. Soos recels hierbo uiteengesit belewe elke mens sy religie (lewensheskouing) op 'n volks-/ kultuureie wyse wat in wisselende mate mag ooreenstem inet die van ander maar ook beslis daarvan afwyk. Daarom kry ons groepe (volke, kulture, gemeenskappe) wat natuurlik ontsıan en bestuan, wie se lede in dieselfde religieuse opset saamgevat kan word maar wat van ander groepe met dieselfde religieuse uitgangspunte tog sodanig kultureel/etnies verskil dat daar verder gedifferensieer sal moet word. Ons kry dus (hisistelike skole en nie-Christelike skole. By eersgenoemule sou daar tot in die oneindige gedifferensieer kon word, byvoorbeeld Protestants-Christelike en RoomsKatoliek-Christelik, maar enige verdeling sal die toets van praktiese moontlikheid moet deurstaan. Dieselfde greld vir die nie-Christelike skole, byvoorbeeld naturalistiese, humanistiese, sosialist iese, kommunistiese, Hindu-, Moslem- ensovoorts skole.

Daar sal byvoorbeeld onder Protestants-Christelike skole nou Blankes, Kleurlinge, Asiërs, Swartes ressorteer. Moet/kan hulle, almal belyclende Christene volgens dieselffe belydenisskrifte, saamgevoeg word en vrughaar ware en egte opvoeding ontvang? Ous glo dat dit beslis nie gewens is nie en sckerlik tot mislukking gedoem is (in ons huidige konstellasic altans). 1)ic egte opvoedkundige siening vereis juis die hele mens in sy totale konteks. Of dit later (oor 50, 100,500 jaar) moontlik sal wees, is nic now ons opdrag nic. Ons moet vandag net sorg dat ons nic die eic politieke beplanning in die plek van dié van God stel en dit dan wil afdwing nie. Ons moet luister en alles doen om die sonde van verdeeldheid, van moedswillige geskeidentheid nie te: bevorder nie. As alles skielik saangegooi word, nooi ous radikale weerstand om die goeie gesindheid te oorheers en ons eiewillige poging tot werktuig vall onmenslikheid te maak. Ons voorsien dis uiteindelik Afrikaanse, Engelse, Kleurling-, Indiër-, Xhosa-, Zoeloe-, 'Tswana- ensovoorts Protestants-Christelike skole wat elk 'n eie etniese/kulturele groep licdien. (Miskien kan ons ook kultuurlose/anti-etniese Christelike skole - nee, valse skole - probeer vir diegene wat ancters wil, maar dis uyns insiens 'n laaste 


\section{B.C. Schutte}

uitweg vir afwykendes.)

Mens mag beviecs wecs dat jy hicrmee nou die weg tot sinlose versplintering en onhantecrbare splintergrocpe geopen leet. Tog kan enige huidige differensiasickriterium tot in dic bespotlike gevoer word, maar logiese, ekonomiesc, historiese en ander cise bepcok so iets tot 'n bruikbare gelieel. Dit behoort ook met dic voorgestelde differensiasie te gebcur, veral as daar voortdurenil op grond van crvaring, navorsing en begrip geskaaf word Watter bestaande stelsel lyk vandag presies soos dit by sy instelling, sê tien juar gelede, gelyk het, terwyl die beginsel tog dieselfde gebly het?

Hicrdie cis van kulturele differensiasic word beslis nie slegs van Blankekant gedoen nie. 'n Swart referent by die jongste kongres van die Kaaplandse Professioncle Onderwysersunie het gesê: "It should also not be surprising, therefore, to anyone why there is this new trend because all the Third World nations are busy planning educational systems that are relevant and mcaningful to their own people and conditions of life". Dit was bes moontlik die cen sonde van die Blankes om aan ander etnicse groepe 'n verwesterde onderwys op tc dring wat hulle swart Westerlinge wou maak in stede van geleerde Swartes (Klcurlinge, Indiërs). Die Blanke (en daarmee saam selfs baie van die ander "geleerdes") het geglo (lie enigste wyse om mense tot berciking van hoogtepunte in dic moderne tegnologiese cra te bring was om van hulle Westerlinge te maak. Orals het dit egter misluk, terwyl Japan en Taiwan getoon het dat hulle op die voorpunt kan staan sonder om te verwesters. Watter pragtige geleenthede word daar nie hiermee aan al die. volke van die $\mathrm{RS} \Lambda$ gebied om hulleself te bly en voorpunt toe te beweeg - as die wil en die deursettingsvernoe daar is (by hulle self en nie noodwendig net by dic regering nic)!

\section{DIE OUERS}

Ons het herhaaldelik van oucrkcuse gepraat: dis die ouets wat die gees en rigting van die skool moet bepaal; dis dic oucrs wat besluit of die bestaande skool 'n Christelike of 'n nic-Christelike skool moet wees; dis die ouers wat liulle volkseie in dic skool waar hulle kinders opvoedende onderwys ontvang, moet vereis; dis die oucrs wat moet toesien dat die aanvullende middele gevind word as die staat se versorgingsbydrae ontoereikend is. Die Christenouers sal verder nok, in same werking met die staat, moet toesien dat die Christ elike karakter van die skool gehandhaal en bevorder word. Dit sal medeverantwoordelikheid meebring vir die aanstelling van die gewenste onderwysers wat prinsipicel en professionecl bevoeg is. As dit die geval is, sal 
die ouers ook 'n hand moet hê in dic werwing van geskikte persone om as onderwysers opgelei te word, en ook in die opleiding self. (Kyk my "Ope brief aan ouers", Die Kerkblad, 84(2608):2 (15/7/81).

Dis vanselfsprekend dat die duisende ouers nie individueel op die skool kan toesak en links en regs eise stel nie. (Die eise wat die voorgestelde stelsel aan die oners stel, geld nie slegs die Christene nie, maar die nie-Christelike skool se ouers het ook dieselfde verpligtinge.) Hierdie ouerreg word deurgaans deur alle kultuurgroepe aanvaar, al is die uillewing daatvan gelorekkig.

Daar sal dus organisasie van gelykgesinde ouers moet kom. Dit legin by die plaaslike vlak vir ouers van elke skool en bring ook saansnoering van die ouerorganisasies van alle gelykgesinde ouers in 'n "streck" (distrik, geografiese gebied, provinsie of ander indeling) mee. So sal streke dan weer saam 'n ouerorganisasie vir die Repulliek vorm, waaruit 'n "ouerraad" sitting in "n "ministeriële raad" kan kry. Dit stel dan die stem van die outer op die verskillende vlakke van belıeer voor: so praat ouers. U mag sê dat so iets onmoontlik is. Onthou net, die meste van die dinge wat vandag bestaan, was in een stadium totaal onmoontlik.

Langs hierdie weg word die CNO-gedagte van staatsondersteunde (algeluele of gedeeltelike steun) groepskole van gelykgesinde ouers 'n werklikheid. Soos CNO altyd beweer het, gun hy nou aan elke andersdenkende en anderskleurige ook alles wat hy vir homself eis.

\section{PARITEIT IN DIE ONDER WYS}

Hierdie saak was 'n besondere opgawe vir die R(BN-kommissie van ondersoek na die onderwys. Een aspek waarin volgens ons volkome gelykheid bereik kan word, word deur die kriterium van lewensbeskoulike differensiasie moontlik gemaak. Die kulturele/etniese kriterium sorg vir verdere gelykheid ten opsigte van kultuureise. In beide voorgaande word gelykheid dan gesien as eiesoortigheid met gelykwaardigheid, wat beslis nie identies (in alle aspekte gelyk) hoef te wees nie. Teen sodanige strewe na gelykheid kan daar geen grondige beswaar ingelsring word nie, al son kurrikulums en selfs sillabusse van mekaar verskil (wecus hulle ciesoortiglieid) maar van dieselfde gehalte is en die gedifferensicerde behoclies in enerse mate bevredig. So verskil die akademiese matrick nic noodwendig van die tegniese matriek in standaard nic maar wel deeglik in inhoud en soort; so aanvaar ons die matriek van elke provinsic en van die GMR vandag as gelykwaardig (maar nic identies nic). 


\section{B.C. Schutte}

Wannecr kurrikulums saamgestel word en daarbinne silabusse oorweeg word, word as vereiste gestel dat dit by die hestaande moct aansluit, dat dit by diegene vir wic dit bedoel is, moet aanpas en deur dic gemiddelde mens vir wie dit saamgestel is, belıartig kan word. Dit beteken dat die universcle sowel as dic differcusiële daarin verdiskontecr moet word, vir almal volgens dieselfde standaarde gemeet. Selfs dic kritcrium van gelykheid vloci dus logies voort uit die basicse kritcrium van lewensbeskoulike diflerensiasie.

Hierdie aspek van dic tockomstige onderwysopset is die grootste twisappel in dic huidige beding. Soos dit hicrbo gestel is, is dit opvoedkundig verantwoordbaar, maar die voorskriftelike kom deesdac ten opsigte van opvoedkundige beplanning dikwels van politici, sommige van wie so radikaal is dat slegs die weg van revolusie hulle sal bevredig en van opvocdkundige cise wcinig teregkom. Baic van wat hierbo voorgestel is en onk van wat van weë die beperkte omvang nie ingesluit kan word nie, is slegs moontlik langs die weg van evolusie of gelejdelike ontwikkeling, tensy die revolusie bygerocp word. Eindpunt wat na dekades, moontlik ecue, bereikbaar mag wees, kan nie oornag met wetgewing reggestel word nic. Ecn so 'n saak is die kwessic van onmiddellike oopstelling van alle skole op alle vlakke vir alle gelowe, volke en individue. Om van diegene wat nog onbevocg is om die standaard van dic grocp wat dic verste gevorder is, te verwag om skiclik bo by te kom, beteken frustrasie en sal lei tot onverantwoordelike middele om te slaag. Word dic standaarde laer gestel om hulle tegemoet te koın, dan geskied dit ten koste van die groep wat die verste gevorder lıet. Beide moontlikhede bly dus verwerplik en gevaarlik. Maar om st imulerend en met alle beskikbare middele alles in die stryd te werp om die onderste vinniger boontoe te laat kom, mede en veral deur eie wil en inspanning, daarteen kan geen besware wees nie. So kan gelykheid dan binne clke gediflerensieerde kultuurgroep bereik word op dieselfde vlak as wat dit by ander groepc bestaan. Saam met hicrdic koorsagtige ywer tot gelyke standaarde moet ook geduld en ewewig beocfen word om te sorg dat die bercikte vlak met die lewensbeskoning harmonicer. Dit vereis verder besliste kontak en wisselwerking tussen kulture, met behoud en opbou van die cie.

\section{TEN BESLUITE}

Ons het getrag om te toon hoedat die beweging om dic beginsel van lewensbeskoulike/religicuse dillerensiasic in die onderwys 'n duidelike geskiedenis gehad het. Ons wou ook toon hoedat dit die cen moontlike weg is om eenheid in ons cnorme verskeidenheid te verkry sonder dat enige seksie. 


\section{Lewensbeskoulike differensiasle}

sy volks- en kultuureie prysgee. Ons het verder probeer aantoon hoe so 'n stelsel kan werk, al sal die toepassing daatvan enorme eise aan moed, vindingrykheid en studie verg. Ons vertrou dat die Suid-Afrika van die toekoms verder deur God gebruik sal word om langs hierdie weg die vrede na te jaag, die naaste te dien, die eic te vertroetel en God te verhecrlik. 